Running head: INHIBITORY CONTROL AND EMOTION REGULATION

\title{
Individual differences in inhibitory control are not related to emotion regulation
}

\author{
Anne Gärtner ${ }^{1}$, Philippe Jawinski² ${ }^{2}$ Alexander Strobel ${ }^{1}$ \\ ${ }^{1}$ Faculty of Psychology, Technische Universität Dresden, Dresden, Germany \\ ${ }^{2}$ Department of Psychology, Humboldt-Universität zu Berlin, Berlin, Germany
}

Word count: 12.797 (including Abstract, Figures, Tables, Captions, References)

Conflict of Interest: None of the authors has a conflict of interest to declare.

Author Note: The dataset analyzed for this study as well as the analysis code are openly available at the Open Science Framework [https://osf.io/2fwm4 and https://osf.io/9gwe7/]

\section{Corresponding author}

Anne Gärtner, PhD

Faculty of Psychology

Technische Universität Dresden

Dresden, Germany

Phone: +49-351-463-36997

Fax: +49-351-463-36993

E-mail: anne_gaertner@tu-dresden.de 


\title{
INHIBITORY CONTROL AND EMOTION REGULATION
}

\begin{abstract}
Although cognitive control and emotional control have been proposed to rely on similar processes, their specific relationship is not well understood. Given that reappraisal to down-regulate negative emotions requires inhibiting or limiting the expression of a prepotent appraisal of a situation in favor of selecting an alternative appraisal, inhibitory control seems to be a particularly relevant process. However, inconsistent findings on the relationship between inhibitory control and reappraisal ability have been reported, likely because of the application of single task measures in relatively small samples. Therefore, this study examined the relationship between both control processes using a powerful within-subject design in a large sample $(N=190)$ and by applying a battery of six commonly used inhibitory control tasks. Emotion regulation was measured comprehensively by self-reported habitual use of reappraisal and suppression strategies, by valence and arousal ratings during a reappraisal task and by concurrent physiological measures such as corrugator electromyography (EMG), skin conductance response (SCR), and heart period (HP). Frequentist and Bayesian analyses indicated that inhibitory control was not associated with emotion regulation in our sample of young healthy adults. Furthermore, by implementing a full two-by-two design including a "regulate neutral" condition, the present study provides evidence that domain-general regulation effects need to be separated from domain-specific regulation effects. Finally, compared to HP and SCR, corrugator EMG emerged as a suitable peripheral physiological indicator of regulatory success that was indicative of the regulation of negative emotion.
\end{abstract}

Keywords: emotion regulation; reappraisal; inhibitory control; cognitive control; peripheral physiology 


\section{INHIBITORY CONTROL AND EMOTION REGULATION}

\section{Introduction}

Emotion regulation plays a major role in our everyday life and is associated with increased well-being and social relationships. Studies uncovering its underlying mechanisms found that emotion regulation is resource-demanding and involves cognitive control processes. Although it is generally assumed that both processes - cognitive and emotional control-share similarities, they have often been studied separately. However, understanding their relationship is important for better understanding emotional well-being as well as mental disorders involving failures in both emotional and cognitive control, such as depression, anxiety and addictive disorders (for reviews see Aldao et al., 2010; Sheppes et al., 2015). Here, we set out to study whether individual differences in a central component of cognitive control, that is, inhibitory control, would predict differences in the ability to regulate emotional responses to negative stimuli in a laboratory setting.

\section{Emotion regulation and inhibitory control}

Emotion regulation can be defined as all processes that aim to influence the intensity, duration and type of emotional experience or expression (Gross, 1998, 2015). One strategy that is commonly discussed in the literature is cognitive reappraisal. The goal of reappraisal is to change the way one appraises the meaning of a situation or stimulus in order to lessen its emotional impact (Gross, 1998, 2015). There are two ways to implement reappraisal: by reinterpretation (also referred to as situation-focused reappraisal) that involves changing one's interpretation of the emotional stimulus or situation, and by detachment (also referred to as distancing or self-focused reappraisal) that involves changing one's personal connection to the emotional stimulus or situation, for example by taking the perspective of an objective observer. Especially detachment has been shown to be among the most effective strategies to down-regulate emotions without negative long-term consequences (for a meta-analysis, see Webb et al., 2012) and will therefore be investigated in the present study.

Reappraisal is a cognitively complex strategy as it draws on various higher cognitive processes; these include language, selective attention, memory, and response selection and inhibition (Ochsner et al., 2012). A plethora of research has already demonstrated that the brain regions that support reappraisal also serve more general, "cold" cognitive control functions (and Ochsner et al., 2012; reviewed in Ochsner \& Gross, 2008). In this regard, especially reappraisal to down-regulate negative emotions requires inhibiting or limiting the expression of a prepotent 


\section{INHIBITORY CONTROL AND EMOTION REGULATION}

appraisal of a situation or stimulus (e.g., as negative) in favor of selecting an alternative appraisal (e.g., as neutral or even positive). Given that these upcoming appraisals and elicited emotions can be understood as prepotent responses, inhibitory control seems to be a particularly relevant process when it comes to their regulation.

Inhibitory control represents a core component of cognitive control and focuses on the ability to actively inhibit or delay a dominant response in order to achieve a goal (Friedman \& Miyake, 2004; Harnishfeger, 1995; MacLeod, 2007; Miyake et al., 2000; Nigg, 2000). It has been reported as an underlying mechanism in different skills and achievements, such as attention, working memory span, problem solving and general cognitive ability (De Beni et al., 1998; Dempster \& Corkill, 1999; Friedman et al., 2007; Pasolunghi et al., 1999). It is also related to reallife problems, such as rumination (De Lissnyder et al., 2010) and problematic eating behavior (Hofmann et al., 2009). Furthermore, deficits in inhibition-related processes are related to various forms of psychopathology, for example depression, substance use disorders, schizophrenia, and autism spectrum disorders (Geurts et al., 2014; Joormann, 2010; Nigg et al., 2006; Westerhausen et al., 2011) - mental disorders that are also characterized by deficits in emotion regulation (Cai et al., 2018; Joormann, 2010; Kober, 2014; Strauss et al., 2013).

Indeed, several lines of research indicate that inhibitory control is related to emotion regulation. First, studies have shown that both are positively correlated. For example, inhibitory control as assessed with the stop-signal and flanker task are positively correlated with reappraisal ability and use of reappraisal strategies in everyday life of healthy adults (N. Cohen et al., 2012; Tabibnia et al., 2011). Second, in preschool children and adolescents, inhibitory control is positively correlated with emotion regulation and use of reappraisal strategies, suggesting common developmental trajectories (Carlson \& Wang, 2007; Hudson \& Jacques, 2014; Lantrip et al., 2016; Rothbart \& Rueda, 2005; Simonds et al., 2007). Third, findings from functional and structural MRI studies report overlapping brain regions to be implicated in both inhibitory control and emotion regulation (cf. Buhle et al., 2014; Cieslik et al., 2015; Dörfel et al., 2014; Kohn et al., 2014; Ochsner \& Gross, 2008); and that gray matter volume in the right ventrolateral prefrontal cortex predicts successful behavioral performance on both an emotion regulation and a stop-signal task (Tabibnia et al., 2011). These findings suggest that both types of controlled behavior may recruit the same neural processes, or at least depend on a large set of shared processes. 


\section{INHIBITORY CONTROL AND EMOTION REGULATION}

However, a handful of studies found no association between inhibitory control and emotion regulation (e.g., McRae et al., 2012) or failed to include a standard behavioral measure of inhibition (e.g., Stawski et al., 2010). Furthermore, although some studies used task batteries in order to measure several cognitive abilities, most of them only used one task per function, for example, the stroop task to measure inhibitory control and the n-back task to measure working memory updating (N. Cohen et al., 2012; Giles et al., 2017; Gyurak et al., 2009, 2012; McRae et al., 2012; Tabibnia et al., 2011). This is a clear limitation of previous studies and might contribute to the inconsistent results, given that no task is a pure measure of a given function under investigation (so-called task impurity problem; Miyake et al., 2000).

To provide a more fruitful and reliable measurement of inhibitory control, the present work combines several tasks that tap inhibitory control and sought to apply a latent variable approach to provide a purer measure of inhibitory control ability — as has already been proposed by Friedman and Miyake (2004). In detail, we followed the approach by Friedman and Miyake and created a similar task battery, that is, we used exactly the same tasks for measuring prepotent response inhibition (stroop task, antisaccade task, stop-signal task) and resistance to distractor interference (Eriksen flanker task, shape-matching task, word-naming task). Furthermore, emotion regulation ability was assessed by using multiple behavioral and peripheral physiological measures in a commonly applied laboratory task.

\section{Peripheral physiological parameters}

Besides the neural changes, emotion regulation also impacts on peripheral systems. Studies revealed characteristic changes in, for instance, heart period (Driscoll et al., 2009; Kalisch et al., 2005), skin conductance (Sheppes et al., 2009; Urry, 2010), and facial muscle activity (Ray et al., 2010; Urry, 2010), indicating that successful reappraisal results in reduced physical activation. In detail, reduced skin conductance responses have been found during down-regulation, and enhanced skin conductance responses during upregulation of negative emotions (Kim \& Hamann, 2012; Plieger et al., 2017; Urry, 2009). Whereas skin conductance is sensitive to changes in arousal, heart period and facial muscle activity are sensitive to changes in valence (Lang et al., 1998). Here, it has been found that down-regulation of negative responses via reappraisal and suppression is associated with deceleration (bradycardia) and upregulation with acceleration (tachycardia) of the heart beat (Dan-Glauser \& Gross, 2011; Demaree et al., 2006; Driscoll et al., 2009; Gross \& Levenson, 1993). Regarding facial muscle activity, up- and downregulation of 


\section{INHIBITORY CONTROL AND EMOTION REGULATION}

negative emotions led to increased and decreased activity of the frowning muscle corrugator supercilii, respectively (Dan-Glauser \& Gross, 2011; Kim \& Hamann, 2012; Lee et al., 2009; Ray et al., 2010).

However, these studies show several limitations: They either merely focused on the reinterpretation type of reappraisal (Urry, 2010), or on suppression (Dan-Glauser \& Gross, 2011; Jackson et al., 2000), or on a mixed form of reappraisal and suppression (Plieger et al., 2017), or on a more general instruction to simply "decrease" negative emotions (Driscoll et al., 2009; Kim \& Hamann, 2012; Ray et al., 2010; Urry, 2009). As far as we know, there are only two studies that investigated the skin conductance response during detachment: one study compared the effects of brain stimulation (tDCS) (Feeser et al., 2014), and the other investigated detachment during emotional film clips (Sheppes et al., 2009). Furthermore, inconsistent results emerged especially regarding the skin conductance response, with some studies showing no modulation during downregulation of negative emotions (Dunn et al., 2009; Kalisch et al., 2005; Kinner et al., 2017). Therefore, by applying a within-subjects design in the largest sample to date, the present study also aimed at clarifying whether heart period, skin conductance, and facial muscle activity are equally suitable to depict emotion regulation success via a detachment strategy.

\section{Present study}

The first goal of the present study was to examine the extent to which inhibitory control is related to successful emotion regulation. To investigate this relationship, we used a powerful within-subjects design, testing participant's inhibitory control abilities on one day and their emotion regulation abilities on another day. Emotion regulation was assessed by using self-reports on habitual use of reappraisal, suppression, and negative affect, as well as the physiological measures of corrugator electromyography, skin conductance response, and heart period during a commonly applied emotion regulation task. Consistent with previous research, we expected frequent use of habitual reappraisal and reduced negative affect, corrugator activity, skin conductance response, and increased heart period during reappraisal to be associated with better performance in inhibitory control.

The second goal of the study was to implement a full two-by-two design by including a "regulate neutral" condition. That is, we wanted to contrast the regulation of negative compared to neutral stimuli. This design allowed us to disentangle domain-specific and domain-general 


\section{INHIBITORY CONTROL AND EMOTION REGULATION}

regulation effects, or in other words, to examine whether the effects of reappraisal generalize across valence categories or not. The former would indicate a general regulation effort that is not specific for negative emotions but rather comprises, for example, the general mindset and processes involved in taking the perspective of an uninvolved observer and implementing the given instruction regardless of the emotional context. The differentiation is a crucial issue as it has important consequences on the general interpretation of the results, but has not been considered in previous studies. We expected that the difference between the permit and detachment condition would be higher during negative compared to neutral pictures.

\section{Methods}

The present research project is diveded in two parts: Whereas the first study examines the structure of inhibitory control as independent research question, the second study examines whether inhibitory control relates to emotion regulation. The first study is already reported in Gärtner and Strobel (2019; data and analysis routines are provided at https://osf.io/2fwm4) and includes a detailed description the six inhibitory control tasks, their zero-order correlations, a latent variable analysis that investigates two sub-components of inhibitory control (that is, prepotent response inhibition and resistance to distractor interference) as well as frequentist analyses comparing reaction time scores and inverse efficiency scores that account for speed-accuracy tradeoffs. The present study builds on these results and reports the findings on the relationship between inhibitory control and emotion regulation as subsequent research question. Data and analysis routines of the present study as well as a list of all measures used in the project can be found at https://osf.io/9gwe7/. We report how we determined our sample size, all data exclusions, all manipulations, and all measures in the study (Simmons et al., 2012).

\section{Participants}

The sample comprised 190 healthy young adults aged 18-39 years $(M=23.8, S D=4.7$; 97 women and 93 men) recruited at the TU Dresden. All participants were non-smokers with German as their mother tongue, had normal or corrected to normal vision and no color blindness, and underwent a semi-structured screening interview for psychiatric or neurological disorders or treatment. None of the participants did report any current or past (in the last year) medical, neurological or psychiatric illness or treatment. The study design was approved by the ethics committee of the TU Dresden. The study was conducted in accordance with the Declaration of 


\section{INHIBITORY CONTROL AND EMOTION REGULATION}

Helsinki and followed the ethical guidelines of the German Psychological Association. All participants provided written informed consent and received compensation for expenses. There was a dropout of one participant at the second testing session (see below), resulting in 189 participants conducting both the inhibitory control battery and the emotion regulation task $\left(M_{\text {age }}=23.8, S D\right.$ $=4.7 ; 96$ women and 93 men).

Sample size determination was based on a tradeoff between time constraints and power considerations. Therefore, we recruited as many participants as possible during a prespecified time window of 12 months. The final sample size of $N=189$ enabled us to detect a correlation between inhibitory control and emotion regulation measures of $r \geq .2$ at an alpha level of .05 with a power of .80 as determined using G*Power 3.1 (Faul et al., 2009). A power plot can be found in Supplementary Figure 1. In two former studies that found a significant association, the correlation between inhibitory control performance and reappraisal success in comparable emotion regulation tasks were $r=.55$ (Tabibnia et al., 2011), and $r=.43$ (Carlson \& Wang, 2007), respectively. However, recent meta-analytically derived effect size estimates suggest that correlations in the range of $r=.20-30$ are generally more likely in the field of individual difference research (e.g., Gignac \& Szodorai, 2016).

\section{Procedure}

After a telephone interview checking basic inclusion criteria (e.g., age, health, and medication), all participants entered the laboratory at T1 completing an inhibitory control battery, and at T2 about two weeks later completing an emotion regulation task. Questionnaires aimed at investigating individual differences in personality traits, negative emotionality, and use of emotion regulation strategies were conducted online between both sessions. Since circadian variation might impact performance in cognitive control tasks as well as skin conductance (Bratzke et al., 2012; Hot et al., 2005, 1999; Schmidt et al., 2007), all sessions were conducted between 9 am and 5 pm. Upon arrival of T1, participants were briefly familiarized with the laboratory setting, informed about the upcoming experiment, gave written informed consent and provided demographic information and ratings on their current mood. Afterwards, participants were randomly assigned to six inhibitory control tasks. At the end of T1, participants were thanked and scheduled for T2. Upon arrival of T2, participants were briefly familiarized with and informed about the upcoming experiment and provided information on their current mood. Then, after electrode placing and a 3-minute rest session the emotion regulation paradigm described below was employed, followed 


\section{INHIBITORY CONTROL AND EMOTION REGULATION}

again by a second 3-minute rest session. Finally, participants were debriefed, reimbursed and thanked. Both sessions lasted approximately 90 minutes each.

\section{Measures and materials}

\section{Emotion-regulation task}

Forty negative and forty neutral pictures were selected from the International Affective Picture Set (IAPS; Lang et al., 1999) and the Emotional Picture System (EmoPics; Wessa et al., 2010; only neutral pictures). Negative pictures were chosen on the basis of low pleasantness $(M \pm$ $S D=2.53 \pm 0.87)$ and high arousal ratings $(M \pm S D=6.0 \pm 0.80)$; neutral pictures were chosen on the basis of moderate pleasantness $(M \pm S D=5.17 \pm 0.51)$ and low arousal ratings $(M \pm S D$ $=2.90 \pm 0.46)$. Picture numbers are given in the Supplementary Material.

The paradigm was based on previous designs to study emotion regulation (Diers et al., 2014; Gärtner et al., 2018; Kanske et al., 2011; McRae et al., 2012). At the beginning of each trial, a picture was presented for $7 \mathrm{~s}$. During the initial $2 \mathrm{~s}$ of this period, a semi-transparent overlay was presented across the center of the picture which contained the instruction for either the "permit" or "detach" condition (instruction phase). During the permit condition, participants were instructed to take a close look at the picture, respond naturally, and to permit any emotions that might arise; during the detach condition, participants were instructed to adopt a neutral, objective, detached, analytic or scientific mindset while viewing the pictures or imagine that the pictured events happened far away in order to feel less negative. Afterwards, the picture was presented alone for the remaining $5 \mathrm{~s}$ (regulation phase). Pictures were presented in a quasi-random order with no more than three trials in a row of the same picture valence or instruction. Immediately following the presentation of each picture, participants were asked to indicate the amount of negative affect and general arousal they felt using a single-item scale, the Affect Grid (Russell, Weiss, \& Mendelsohn, 1989; German version: Uhmann, Wendsche, Tomaschek, \& Richter, 2008). The Affect Grid was anchored by "highly unpleasant" and "highly pleasant" on the x-axis and "very aroused" and "not at all aroused" on the y-axis, respectively. The rating period lasted $4 \mathrm{~s}$ (maximum). Subsequently, a fixation cross was presented with a jitter of $5.5-9.5 \mathrm{~s}$ (7.5 s on average). The emotion regulation task lasted approximately 20 minutes. While the sequence of the pictures was fixed, the order of the instructions was reversed for half of the participants (see Supplementary Material for further details). 


\section{INHIBITORY CONTROL AND EMOTION REGULATION}

As reported above, we used a full two-by-two design including a "regulate neutral" condition. Usually, this condition is omitted in order to avoid confusion about how to regulate processes to pictures that elicit little or no emotion (e.g., Moser et al., 2014). Therefore, an example instruction that was given for reappraise neutral trial was "even if you do not experience the picture to be very emotional, you should maintain the regulation instruction and detach yourself from the meaning of the picture to further neutralize your experience of the picture.". To ensure better comparability with other studies that excluded the "regulate neutral" condition, we report both the commonly used difference between "permit negative" and "detach negative" as well as the full interaction effect including the "permit neutral" and "detach neutral" condition.

\section{Physiological data collection and reduction}

Facial EMG was measured over the corrugator supercilii as an index of affective valence (Bradley \& Lang, 2000). Two $\mathrm{Ag}-\mathrm{AgCl}$ electrodes with $4 \mathrm{~mm}$ inner diameter were placed over the left and right corrugator supercilii muscle (as suggested in Fridlund \& Cacioppo, 1986). We applied electrodes on both sided of the face to investigate potential differences and consistency. Impedance level was kept below $10 \mathrm{k} \Omega$. Raw signals were amplified by a BrainAmp amplifier (Brain Products GmbH, Gilching, Germany), sampled at $1000 \mathrm{~Hz}$, filtered (low-pass: $500 \mathrm{~Hz}$; high-pass: $30 \mathrm{~Hz}$; band-stop filter: $50 \mathrm{~Hz}$ ), rectified and integrated. Corrugator EMG was analyzed during the $7 \mathrm{~s}$ of picture viewing. The data were baseline corrected using a time window of $2 \mathrm{~s}$ prior to stimulus onset as reference. Each trial and channel were visually inspected for artefacts. Corrugator EMG was averaged for each condition and each participant.

Skin conductance response (SCR) was measured on the distal phalanges of index and middle finger of the non-dominant left hand leaving the right hand free for handling the mouse during the experiment. Raw signals were amplified by a BrainAmp amplifier (Brain Products GmbH, Gilching, Germany), sampled at $1000 \mathrm{~Hz}$. Single trial-wise SCR was analyzed offline using the SCRalyze toolbox (Bach et al., 2009) implemented in PsPM for model-based analysis of peripheral psychophysiology measurements. This modelling method appears to be more powerful for SCR analysis than conventional (peak scoring) analysis of SCR (Bach, 2014; Bach et al., 2010). In detail, we applied the implemented non-linear model for event-related SCR. This approach estimates the onset and amplitude of the canonical response function within a specified time window and even allows the analysis of multiple and overlapping SCRs (Bach et al., 2011). As we merely predicted a SCR some time during the picture presentation period (onset within or after the first 


\section{INHIBITORY CONTROL AND EMOTION REGULATION}

$2 \mathrm{~s}$ of instruction presentation), we set the time window to cover the full picture presentation period (7 s). SCR data was down-sampled to $10 \mathrm{~Hz}$ and bandpass filtered with a first order Butter-worth filter (high-pass: $0.05 \mathrm{~Hz}$, low-pass: $1.0 \mathrm{~Hz}$ ). As recommended in Bach et al. (2009), SCR data were normalized and mean-centered to reduce inter-subject differences in the response amplitude originating from other peripheral factors (e.g., skin properties). To infer sudomotor nerve activity, responses were estimated in a trial-by-trial fashion and condition-specific estimates were obtained by averaging across all trials of the same condition for each participant. 12 participants were classified as non-responders and excluded from the analysis.

Electrocardiography (ECG) data were recorded by two electrodes attached to the left and right forearms. Raw signals were amplified by a BrainAmp amplifier (Brain Products GmbH, Gilching, Germany), sampled at $1000 \mathrm{~Hz}$, filtered (high-pass: $5 \mathrm{~Hz}$, low-pass: $30 \mathrm{~Hz}$ ) and segmented. Because our picture presentation was longer than $1 \mathrm{~s}$ that was used for modeling event-related heart period responses using PsPM (Paulus et al., 2016), analyses were done with Brain Vision Analyzer. $\mathrm{R}$ peaks were detected using the pulse artifact correction algorithm and verified by visual inspection. Heart periods (cf. Gross \& Levenson, 1993) were obtained by measuring the interbeat interval (IBI), that is, the time difference in ms between two consecutive $\mathrm{R}$ peaks (IBI is the inverse of heart rate and was chosen because of its better statistical properties, see Berntson et al., 2016). At each $\mathrm{R}$ peak, an IBI marker was set that indicated the distance to the preceding $\mathrm{R}$ peak. IBIs that were 2.58 standard deviations above or below the mean IBI were regarded as outliers and excluded from the analysis. IBI markers that occurred within $2 \mathrm{~s}$ before each trial onset served to calculate the mean heart period at baseline. IBI markers that occurred within the first $6 \mathrm{~s}$ of each trial served to calculate the mean trial heart period. Baseline-corrected heart periods were assessed in a trial-by-trial fashion and condition-specific estimates were obtained by averaging across all trials of the same condition for each participant.

\section{Self-report measure of emotion regulation}

Individual differences in the use of cognitive emotion regulation strategies may modulate task performance in the emotion regulation task and have been shown to be associated with inhibitory control (Carlson \& Wang, 2007; N. Cohen et al., 2012; Lantrip et al., 2016; Tabibnia et al., 2011). Therefore, the German version of the Emotion Regulation Questionnaire (ERQ; Abler \& Kessler, 2009) was used to assess the habitual use of reappraisal and suppression. 


\section{INHIBITORY CONTROL AND EMOTION REGULATION}

\section{Inhibitory control task battery}

Six tasks were used to assess the participants' inhibitory control abilities; three for prepotent response inhibition (antisaccade task, stop-signal task, stroop task) and three for resistance to distractor interference (Eriksen flanker task, shape-matching task, word-naming task), all adapted from Friedman and Miyake (2004). The tasks were presented in random order across participants to control for order effects. A detailed description of all tasks and the data trimming procedure can be found in Gärtner \& Strobel (2019).

\section{Data acquisition and statistical analysis}

Behavioral data were acquired using Presentation@ (Version 17.0, Neurobehavioral Systems, Inc., Berkeley, CA, www.neurobs.com), running at LCD screens with a resolution of 1080 $\times$ 1024. Questionnaire responses were recorded using Limesurvey (http://www.limesurvey.org). Behavioral and questionnaire data were analyzed using SPSS Statistics for Macintosh (Version 22; IBM Corp., Armok, NY, USA), Matlab 2017b (Math-Works, Natick, MA, USA) and RStudio (Version 1.1.463; RStudio Team, 2016) with $R$ (Version 3.6.1; R Core Team, 2018).

All variables were examined for normality and outliers using boxplots, QQ-plots and Shapiro-Wilk tests. Several variables were not normally distributed (Kolmogorov-Smirnov tests, $p$ $<.20$; Shapiro-Wilk tests, $p<.05)$. Therefore, we used non-parametric Wilcoxon tests for paired samples to examine the impact of emotion regulation on self-reported valence, arousal, corrugator EMG, SCR, HP, and behavioral measures (the results did not differ from a parametric repeated measures ANOVA). Effect sizes are indicated by Kendall's W (coefficient of concordance), which is directly equivalent to eta squared in ANOVA tests. Furthermore, we used Spearman's rho $\left(r_{s}\right)$ correlations to investigate the inter-correlations between performance in the inhibitory control tasks and the emotion regulation measures. Correction for multiple testing was done by the FDR method according to Benjamini and Hochberg (1995).

Regarding corrugator EMG, exploratory analyses indicated that there were no differences between left and right corrugator response (data not shown). Therefore, all analyses were conducted with the averaged bilateral corrugator response. Regarding the emotion regulation task, we report the interaction effect resulting from the full two-by-two design, that is, we compare the difference between the "regulate negative" condition (detach vs. permit) with the "regulate neutral" condition (detach vs. permit). However, to ensure better comparability with previous studies that omitted 


\section{INHIBITORY CONTROL AND EMOTION REGULATION}

the "regulate neutral" condition, we additionally report the results for the "regulate negative" condition only.

Data trimming, statistical analyses and descriptive statistics of the inhibitory control tasks are described in Gärtner and Strobel (2019). Briefly, mean reaction times and error rates were negatively correlated in most of the inhibitory control tasks, indicating speed-accuracy tradeoffs, that is, faster responses at the expense of more errors (Friedman \& Miyake, 2004; Miyake et al., 2000). Therefore, performance in these tasks could not be appropriately quantified by difference scores based on reaction times alone. Hence, we computed inverse efficiency scores (IES) that combine reaction times and error rates in a single score, as has also been done previously in the literature (cf. Wolff et al., 2016). Further, we applied a latent variable analysis in order to move beyond the investigation of bivariate relationships. By extracting common variance that is shared by all tasks, measurement error and systematic variance that is attributable to idiosyncratic task demands can be reduced, and a purer measure of inhibitory control can be obtained for further analyses on the relation with emotion regulation. Results are shown for both bivariate relationships and the latent factor extracted from the six inhibitory control tasks. Because previous studies did not apply IES when comparing performance in inhibitory control tasks and emotion regulation (e.g., Carlson \& Wang, 2007; N. Cohen et al., 2012; Lantrip et al., 2016; Tabibnia et al., 2011), we repeated all analyses using standard reaction time difference scores to increase comparability with other studies.

\section{Results}

\section{Valence and arousal ratings}

There were statistically significant differences in arousal and valence ratings across conditions (see Figure 1). In detail, negative pictures were rated significantly more arousing than neutral pictures $\left(\chi^{2}(1)=183.02, p<.001\right.$, Kendall's $\left.W=.97\right)$ and pictures during permit were rated significantly more arousing than during detach $\left(\chi^{2}(1)=167.54, p<.001\right.$, Kendall's $\left.W=.89\right)$. In addition, the difference between permit and detach was more pronounced for negative than for neutral stimuli $\left(\chi^{2}(1)=72.27, p<.001\right.$, Kendall's $\left.W=.38\right)$, indicating a significant interaction effect. When investigating only negative pictures, arousal was significantly higher during permit than during detach $\left(\chi^{2}(1)=178.09, p<.001\right.$, Kendall's $\left.W=.95\right)$. Regarding valence, negative pictures were rated significantly more negative than neutral pictures $\left(\chi^{2}(1)=188.00, p<.001\right.$, Kendall's $\left.W=1.00\right)$. 


\section{INHIBITORY CONTROL AND EMOTION REGULATION}

Further, pictures during permit were not generally rated more negative than during detach $\left(\chi^{2}(1)=0.93, p=.334\right.$, Kendall's $\left.W=.01\right)$. However, valence ratings decreased during detachment from negative pictures, while there was an increase during detachment from neutral trials. The observed changes significantly differed between negative and neutral trials $\left(\chi^{2}(1)=74.80, p<.001\right.$, Kendall's $W$ $=.40$ ), indicating a significant interaction effect. When investigating only negative pictures, valence was rated significantly more negative during permit than during detach $\left(\chi^{2}(1)=144.60, p<.001\right.$, Kendall's $W=.77)$.
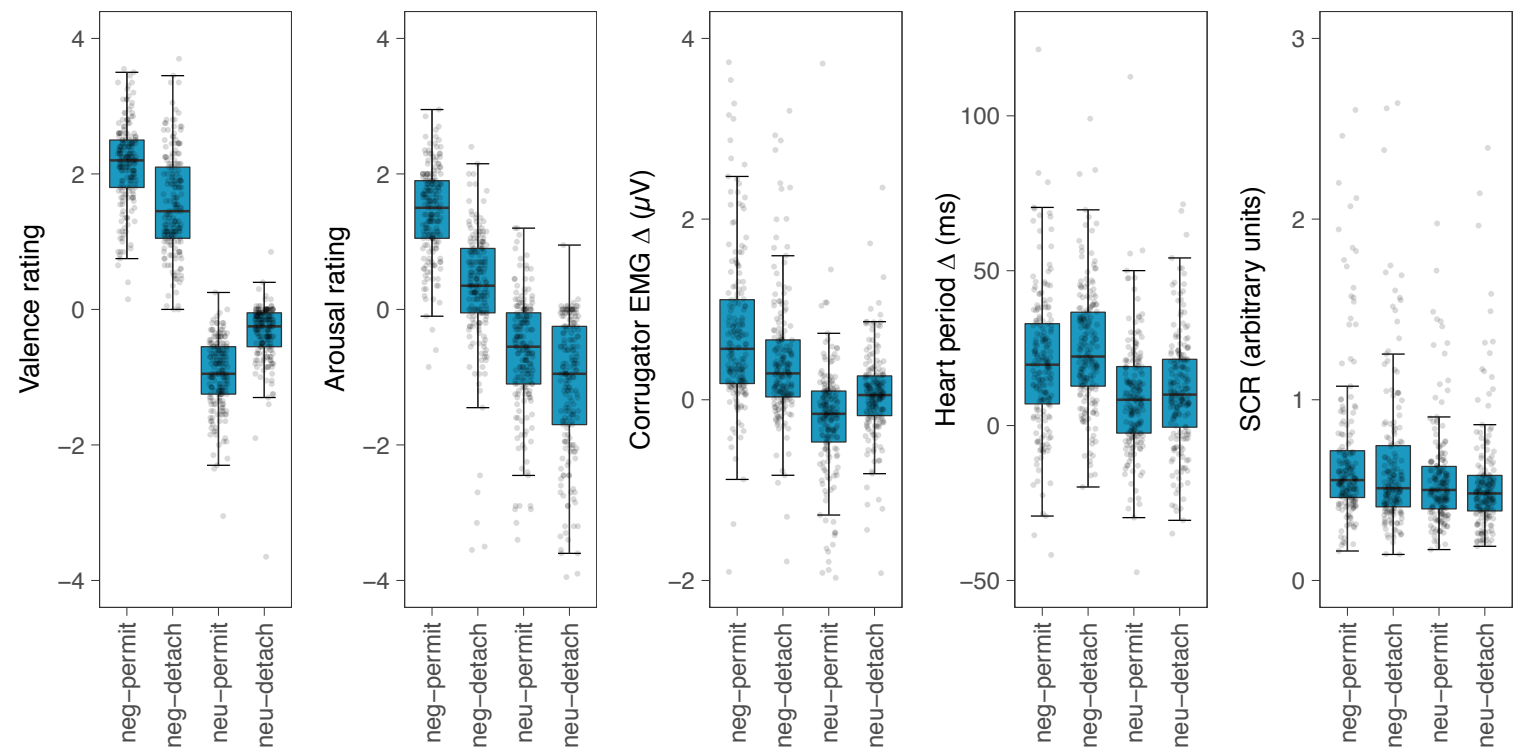

Figure 1 Boxplots of valence and arousal ratings $(-4=$ highly pleasant $/$ not at all aroused, $4=$ highly unpleasant/very aroused), corrugator EMG, heart period, and skin conductance response (SCR) across conditions. Delta represents difference to baseline. Descriptive statistics can be found in Supplementary Table 1.

\section{Corrugator EMG}

Results of separate repeated measures Friedman ANOVAs demonstrated statistically significant differences in corrugator EMG responses across conditions (see Figure 1). In detail, negative pictures elicited a stronger corrugator EMG response than neutral pictures, $\left(\chi^{2}(1)=151.12, p<.001\right.$, Kendall's $W=.80)$. There was no significant main effect of strategy, $\left(\chi^{2}(1)=0.13, p=.716\right.$, Kendall's $W=.00)$, but a significant interaction effect of valence and strategy, $\left(\chi^{2}(1)=82.67, p<.001\right.$, Kendall's $W=.44$ ), indicating a stronger increase in corrugator activity during permit compared to detach for negative compared to neutral pictures. When investigating only negative pictures, corrugator activity 


\section{INHIBITORY CONTROL AND EMOTION REGULATION}

was significantly higher during permit compared to detach $\left(\chi^{2}(1)=28.20, p<.001\right.$, Kendall's $W=$ $.15)$.

\section{Heart period}

Results of separate repeated measures Friedman ANOVAs demonstrated statistically significant differences in heart periods across conditions (see Figure 1). In detail, negative pictures were associated with increased heart periods compared to neutral pictures $\left(\chi^{2}(1)=56.13, p>.001\right.$, Kendall's $W=.30)$. Notably, pictures during detach were associated with increased heart periods compared to permit $\left(\chi^{2}(1)=9.78, p=.002\right.$, Kendall's $\left.W=.05\right)$. The difference between permit and detach was similar for negative and for neutral pictures $\left(\chi^{2}(1)=0.13, p=.72\right.$, Kendall's $\left.W=.00\right)$, indicating no significant interaction effect. When investigating only negative pictures, heart periods were significantly increased during detach compared to permit $\left(\chi^{2}(1)=8.89, p=.003\right.$, Kendall's $W=.05)$.

\section{Skin conductance response}

Results of separate repeated measures Friedman ANOVAs demonstrated statistically significant differences in skin conductance responses across conditions (see Figure 1). In detail, negative pictures elicited significantly higher SCRs than neutral pictures $\left(\chi^{2}(1)=5.82, p=.016\right.$, Kendall's $W=.03)$ and pictures during permit elicited significantly higher SCRs than pictures during detach $\left(\chi^{2}(1)=3.84, p=.05\right.$, Kendall's $\left.W=.02\right)$. However, the difference between permit and detach was not more pronounced for negative than for neutral stimuli $\left(\chi^{2}(1)=0.09, p=.763\right.$, Kendall's $W=.00$ ), indicating no significant interaction effect. When investigating only negative pictures, skin conductance responses were significantly higher during permit than during detach $\left(\chi^{2}(1)=8.21, p=.004\right.$, Kendall's $\left.W=.05\right)$.

\section{Correlations among emotion regulation measures}

Correlations among the emotion regulation measures are shown in Table 1. In sum, when investigating only negative pictures during permit vs. detach, regulation success as indicated by valence ratings was positively correlated with regulation success as indicated by arousal ratings $\left(r_{s}=\right.$ $.52, p<.001)$. Furthermore, regulation success as indicated by arousal ratings was positively correlated with regulation success as indicated by SCR $\left(r_{s}=.16, p=.033\right)$, and regulation success as indicated by corrugator activity was positively correlated with regulation success as indicated by 


\section{INHIBITORY CONTROL AND EMOTION REGULATION}

SCR $\left(r_{s}=.18, p=.019\right)$. There were no significant correlations with habitual use of reappraisal and suppression.

Table 1 Spearman correlations of emotion regulation success parameters

\begin{tabular}{lccccccc}
\hline & Valence & Arousal & $\begin{array}{c}\text { Corr } \\
\text { EMG }\end{array}$ & HP & SCR & $\begin{array}{c}\text { ERQ- } \\
\text { Reap }\end{array}$ & $\begin{array}{c}\text { ERQ- } \\
\text { Supp }\end{array}$ \\
\hline Valence & - & $.20^{* *}$ & .09 & $-.17^{*}$ & .06 & -.10 & -.02 \\
Arousal & $.52^{* * *}$ & - & .02 & .06 & .13 & -.10 & -.05 \\
Corr EMG & .12 & .14 & - & -.03 & $.17^{*}$ & -.04 & -.03 \\
HP & -.14 & -.09 & -.04 & - & -.10 & $.15^{*}$ & -.03 \\
SCR & .04 & $.16^{*}$ & $.18^{*}$ & -.02 & - & .03 & -.02 \\
ERQ-Reap & -.06 & -.10 & -.06 & .11 & .12 & - & -.06 \\
ERQ-Supp & .07 & -.05 & -.08 & $>.01$ & -.08 & -.06 & - \\
\hline
\end{tabular}

Note. Corr EMG, corrugator electromyography; HP, heart period; SCR, skin conductance response; ERQ-Reap, ERQ reappraisal scale; ERQ-Supp, ERQ suppression scale. Values below the diagonal line indicate emotion regulation success when investigating only negative pictures ( $\left.\mathrm{NEG}_{\text {permit-detach }}\right)$; values above the diagonal line indicate emotion regulation success when including the "regulate neutral" condition $\left(\mathrm{NEG}_{\text {permit-detach }}-\mathrm{NEU}_{\text {permit-detach }}\right) .{ }^{*} p<.05 ;{ }^{* *} p<.01 ;{ }^{* *} p<.001$.

When investigating the interaction effect and thereby taking the "regulate neutral" condition

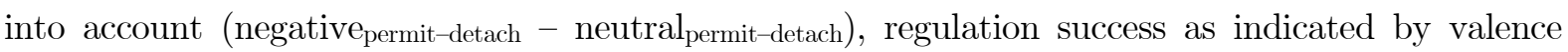
ratings was still positively correlated with regulation success as indicated by arousal ratings $\left(r_{s}=.20\right.$, $p=.005)$, and regulation success as indicated by corrugator activity was still positively correlated with regulation success as indicated by SCR $\left(r_{s}=.17, p=.025\right)$. Additionally, regulation success as indicated by valence ratings was negatively correlated with regulation success as indicated by heart periods $\left(r_{s}=-.17, p=.019\right)$; and regulation success as indicated by heart periods was positively correlated with habitual use of reappraisal $\left(r_{s}=.15, p=.046\right)$. There were no significant associations between arousal and corrugator or SCR.

\section{Inhibitory control performance}

Descriptive statistics (mean, standard deviation, range, skew, kurtosis, reliability) and bivariate correlations among the six inhibitory control tasks can be found in Gärtner and Strobel (2019). As reported previously, performance in the stroop task correlated positively with the performance in the shape-matching task $\left(r_{s}=.21, p=.004\right)$. Furthermore, performance in the 


\section{INHIBITORY CONTROL AND EMOTION REGULATION}

antisaccade task correlated positively with the performance in the stop-signal $\left(r_{s}=.19, p=.009\right)$, shape-matching $\left(r_{s}=.18, p=.015\right)$, and word-naming task $\left(r_{s}=.18, p=.012\right)$. There were no further correlations between the tasks. By applying a latent variable analysis, a one-factor model with the latent variable response-distractor inhibition emerged with good fit to the data (note that only four out of six tasks demonstrated significant factor loadings, see Gärtner and Strobel (2019)).

\section{The relationship between inhibitory control and emotion regulation}

Bivariate correlations between the six inhibitory control tasks, the latent variable response-distractor inhibition and the emotion regulation parameters are presented in Table 2.

[Table 2 about here]

As can be seen in Table 2, there were three nominal significant correlations. Performance in the antisaccade task was negatively correlated with habitual use of reappraisal, indicating that better performance (lower IES) was associated with increased use of reappraisal. Furthermore, when investigating only negative pictures, there was a negative correlation between performance in the shape-matching task and reduction in corrugator EMG during reappraisal, indicating that better performance was associated with better regulation, that is, a stronger decrease in corrugator activity during negative detach vs. permit. Against our hypothesis, there was also a positive correlation between performance in the shape-matching task and SCR during reappraisal, indicating that better performance was associated with decreased regulation success in SCR during negative detach vs. permit. However, none of the correlations survived correction for multiple comparisons using the FDR method according to Benjamini and Hochberg.

There was no nominal significant association when including the "regulate neutral" condition, and the latent variable response-distractor inhibition was not significantly related to any of the emotion regulation parameters. Further, the magnitudes of the correlations between performance in the emotion regulation and inhibitory control tasks were generally low (most of them less than $r=.1$ ), indicating rather negligible effects even if they were significant.

Because previous studies did not apply inverse efficiency scores when comparing performance in inhibitory control tasks and emotion regulation, we repeated all analyses using standard reaction time difference scores to increase comparability with other studies (see Supplementary Table 2). However, out of four nominal significant correlations, none survived 


\section{INHIBITORY CONTROL AND EMOTION REGULATION}

correction for multiple testing, indicating that inhibitory control was not robustly associated with any of the emotion regulation measures.

To further strengthen this assumption, we generated a permutation-based QQ-plot comparing the observed $p$-values from the correlation analyses with the expected $p$-values under the null hypothesis (see Supplementary Figure 2). The QQ-plot does not suggest that the distribution of observed $p$-values in our sample differs from a random distribution under the null hypothesis.

Lastly, because classical null hypothesis testing (NHST) only allows to reject the null hypothesis, we calculated Bayes Factors to quantify the strength of evidence (directly interpretable as an odds ratio) for the null hypothesis $\left(\mathrm{BF}_{01}\right)$. These analyses were run post-hoc with JASP (Version 0.9.0.1; JASP Team, 2018). The results are detailed in Supplementary Table 3. In sum, the majority of associations reported in Table $2(70 \%)$ showed Bayes Factors that suggest anecdotal to moderate evidence in favor of the $\mathrm{H} 0\left(1.4 \leq \mathrm{BF}_{01}<10\right)$, while some $(30 \%)$ even demonstrated strong evidence in favor of the $\mathrm{H} 0\left(10 \leq \mathrm{BF}_{01} \leq 11\right)$. That is, the data were about 1.4 to 11 times more likely under the assumption of the null hypothesis than under the assumption of the alternative hypothesis. Therefore, both the frequentist approach and the Bayesian approach suggested that inhibitory control was not substantially related to emotion regulation in our sample. 


\section{INHIBITORY CONTROL AND EMOTION REGULATION}

Table 2 Spearman correlations between performance in inhibitory control tasks (inverse efficiency scores, IES) and emotion regulation measures

\begin{tabular}{|c|c|c|c|c|c|c|c|c|c|c|c|c|c|c|c|c|c|c|c|c|c|}
\hline & \multicolumn{3}{|c|}{ IES Antisaccade } & \multicolumn{3}{|c|}{ Stop-Signal $^{\circ}$} & \multicolumn{3}{|c|}{ IES Stroop } & \multicolumn{3}{|c|}{ IES Flanker } & \multicolumn{3}{|c|}{$\begin{array}{c}\text { IES Shape- } \\
\text { matching }\end{array}$} & \multicolumn{3}{|c|}{ IES Word-naming } & \multicolumn{3}{|c|}{$\begin{array}{c}\text { Response-Distractor } \\
\text { Inhibition }\end{array}$} \\
\hline & rho & $p$ & FDR & rho & $p$ & FDR & rho & $p$ & FDR & rho & $p$ & FDR & rho & $p$ & FDR & rho & $p$ & FDR & rho & $p$ & FDR \\
\hline \multicolumn{22}{|c|}{ Emotion regulation success } \\
\hline \multicolumn{22}{|c|}{ NEG permit-detach } \\
\hline Valence & -.082 & .264 & .892 & .050 & .494 & .906 & -.121 & .097 & .870 & .097 & .184 & .870 & .006 & .933 & .992 & -.046 & .532 & .906 & -.065 & .377 & .906 \\
\hline Arousal & -.100 & .173 & .870 & -.023 & .756 & .952 & -.077 & .293 & .906 & .100 & .171 & .870 & .041 & .576 & .906 & .022 & .760 & .952 & -.016 & .827 & .952 \\
\hline EMG & -.036 & .625 & .906 & .071 & .332 & .906 & -.061 & .403 & .906 & -.034 & .646 & .920 & -.148 & .042 & $.870^{*}$ & .081 & .267 & .892 & -.063 & .387 & .906 \\
\hline SCR & -.039 & .610 & .906 & .049 & .517 & .906 & .026 & .729 & .952 & -.076 & .316 & .906 & .154 & .041 & $.870^{*}$ & .052 & .495 & .906 & .098 & .196 & .870 \\
\hline $\mathrm{HP}$ & .031 & .668 & .936 & .002 & .983 & .993 & .022 & .761 & .952 & -.019 & .798 & .952 & .017 & .817 & .952 & -.093 & .202 & .870 & .018 & .808 & .952 \\
\hline \multicolumn{22}{|c|}{$\mathrm{NEG}_{\text {permit-detach }}-\mathrm{NEU}_{\text {permit-detach }}$} \\
\hline Valence & -.092 & .209 & .870 & .009 & .904 & .992 & -.103 & .160 & .870 & .117 & .110 & .870 & .001 & .993 & .993 & -.050 & .495 & .906 & -.063 & .386 & .906 \\
\hline Arousal & .047 & .519 & .906 & -.023 & .753 & .952 & -.097 & .184 & .870 & .080 & .276 & .892 & .037 & .618 & .906 & .010 & .891 & .992 & .007 & .926 & .992 \\
\hline EMG & .057 & .435 & .906 & .038 & .605 & .906 & .007 & .923 & .992 & -.028 & .706 & .952 & -.090 & .220 & .870 & .133 & .069 & .870 & .016 & .824 & .952 \\
\hline SCR & -.091 & .230 & .870 & .040 & .601 & .906 & .005 & .947 & .993 & -.069 & .364 & .906 & .047 & .534 & .906 & .040 & .596 & .906 & -.003 & .973 & .993 \\
\hline $\mathrm{HP}$ & .050 & .496 & .906 & .021 & .772 & .952 & .036 & .625 & .906 & -.117 & .108 & .870 & .098 & .179 & .870 & -.046 & .532 & .906 & .054 & .464 & .906 \\
\hline \multicolumn{22}{|l|}{ ERQ self-report } \\
\hline Reappraisal & -.147 & .044 & $.870^{*}$ & -.089 & .222 & .870 & -.060 & .410 & .906 & -.086 & .238 & .870 & .001 & .990 & .993 & .057 & .438 & .906 & -.054 & .461 & .906 \\
\hline Suppression & -.128 & .080 & .870 & -.036 & .620 & .906 & .062 & .397 & .906 & .134 & .067 & .870 & .019 & .798 & .952 & -.106 & .146 & .870 & -.013 & .857 & .973 \\
\hline
\end{tabular}

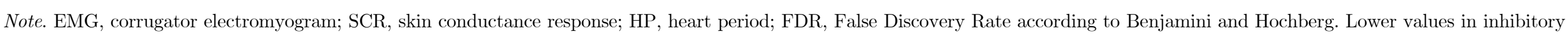

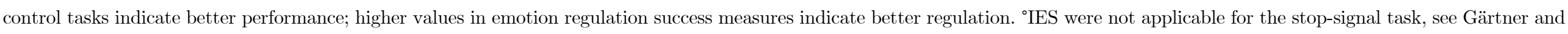
Strobel (2019). * indicates two-sided nominal significance with $p<.05$. 


\section{Discussion}

The first goal of this study was to investigate the relationship between a central component of executive function, inhibitory control, and emotion regulation. By using a powerful within-subjects design, we tested participants' inhibitory control abilities in six well-validated behavioral tasks on one day and their emotion regulation abilities in a common laboratory paradigm on another day. As expected, reappraisal via a detachment strategy resulted in reduced negative affect, arousal, corrugator EMG, SCR, and increased HP compared to the viewing condition. Furthermore, we observed robust interference effects in all inhibitory control tasks, indicating that our design was implemented successfully. However, there were no meaningful associations between any of the inhibitory control and emotion regulation measures. Instead, further analyses suggested that the two control processes are not related at the behavioral level in our sample of young healthy adults.

The second goal was to implement a full two-by-two design by including a "regulate neutral" condition and to investigate whether the effects of reappraisal generalize across valence categories or not. Results indicated corrugator EMG as the only physiological predictor of emotion regulation success that is indicative for the regulation of negative (compared to neutral) emotions. Furthermore, corrugator EMG showed a considerable effect size with $44 \%$ of variance explanation, suggesting this peripheral physiological parameter as useful indicator of regulation success.

\section{Emotion regulation and inhibitory control}

Regarding the reappraisal task, detachment resulted in reduced negative valence and arousal. Furthermore, in line with previous studies (Driscoll et al., 2009; Kalisch et al., 2005; Ray et al., 2010; Sheppes et al., 2009; Urry, 2010), detachment modulated physiological responses and went along with reduced corrugator activity, reduced SCR, and increased HP compared to the permit condition. Similarly, reduced negative valence correlated positively with reduced arousal; and reduced corrugator EMG correlated positively with reduced SCR. Regarding inhibitory control, we observed robust interference effects in all tasks, indicating that we implemented the design successfully. Nevertheless, we observed only small and partly non-significant zero-order correlations between performance in the tasks, thereby echoing previous findings in the literature that highlight the well-known task impurity problem in the context of executive function tasks (cf. Friedman \& Miyake, 2004; Miyake et al., 2000; Miyake \& Friedman, 2012). To alleviate this, we applied a latent variable analysis to extract variance that is common to all tasks. Indeed, a single factor response- 


\section{INHIBITORY CONTROL AND EMOTION REGULATION}

distractor inhibition emerged and was used for further analyses (see Gärtner and Strobel (2019) for a detailed discussion. However, despite these thoughtful methodological considerations, neither the latent variable nor performance in the six inhibitory control tasks was robustly related to successful emotion regulation.

The present study investigated the relationship between the two control processes comprehensively with sufficient power to detect effect sizes of $r \geq .20$ (see "Methods"). Indeed, we observed three nominally significant associations between performance in the antisaccade task and habitual use of reappraisal, and performance in the shape-matching task and reduced corrugator EMG and - contrary to our hypotheses - increased SCR, respectively. However, none of these associations survived correction for multiple testing.

The median of the absolute effect size across all correlations displayed in Table 2 was $r$ $=.05$. By Cohen's standards, this is a smaller than small correlation (J. Cohen, 1988). Yet, is has been argued recently and not for the first time, that the classical standards may underestimate the importance of an effect and that researchers should not routinely dismiss what by these standards would deem small effects (Funder \& Ozer, 2019). Rather one should consider the possible consequences of an effect in the long run. To visualize such consequences, Funder and Ozer (2019) suggest binomial effect size displays. Imagine a $2 \times 2$ table of 200 individuals suffering from some disease, the half of which received an intervention. A correlation of $r=0$ between the intervention and the outcome would result in equally sized cells of $n=50$. In the case of a correlation of $r=$ .30 , the result would be that in the intervention group, $n=65$ individuals would have recovered as opposed to $n=35$ who had not, while in the group without intervention, only $n=35$ would have recovered as opposed to $n=65$ who had not (to get these numbers, one multiplies the correlation by 100, divides the result by 2 and adds one fourth of the total sample size). Now what would be the numbers in case of a correlation of $r=.05$ ? Here, $n=52-53$ individuals in the intervention group would have recovered as opposed to $n=47-48$ individuals who had not. If having not recovered means being dead after having not received intervention, this is certainly not a negligible effect size. If having not recovered means failing with emotion regulation when exhibiting low inhibitory control, and if the research aim was to learn about the role of inhibitory control in emotion regulation, then an effect size of $r=.05$ suggests a minor role if any.

Because null hypothesis testing does only allow to reject the null hypothesis, we further created a QQ-plot to illustrate the observed vs. expected $p$-values under the null hypothesis, and we reanalyzed the data with a Bayesian approach to examine whether the data supports evidence 


\section{INHIBITORY CONTROL AND EMOTION REGULATION}

for the null hypothesis. In fact, results indicated that the distribution of observed $p$-values in our sample did not differ from a random distribution under the null hypothesis. In a similar vein, Bayes factors for the respective correlation coefficients indicated that the data were about 1 to 10 times more likely under the assumption of the null than alternative hypothesis. Thus, on the basis of the statistical power and the consistent results across analyses approaches, we conclude that inhibitory control was not robustly associated with any of the emotion regulation measures in our sample in a cross-sectional, behavioral design.

This finding is in contrast to previous studies (e.g., Carlson \& Wang, 2007; N. Cohen et al., 2012; Lantrip et al., 2016; Tabibnia et al., 2011). For example, Tabibnia and colleagues (2011) found a positive relationship between performance in the stop-signal task and reappraisal success. However, their study differed from ours with regard to the sample size, which is comparatively small $(N=18)$ and represents a clear limitation (see Schönbrodt \& Perugini, 2013). Furthermore, as has also been pointed out by others (Schmeichel \& Tang, 2015), the investigation of bivariate relationships is limited, as performance in complex cognitive tasks is not process pure but includes idiosyncratic task requirements and measurement error. Thus, multiple measures of the same construct are necessary to obtain purer measures of the underlying function (Friedman \& Miyake, 2004; Miyake et al., 2000; Miyake \& Friedman, 2012). This is why the present work investigated a task battery and applied a latent variable approach. Although the latent variable responsedistractor inhibition could be extracted, this variable was not related to any of the emotion regulation measures (all $p \geq .19$ ), challenging the view that even a more process-pure measure of inhibitory control is meaningfully related to emotion regulation.

Instead, our results are in line with other studies that also found null effects (Beauchamp et al., 2016; Depue et al., 2016; McRae et al., 2012). Thus, a possible explanation could be that inhibitory control constitutes such a routine or fundamental process in emotion regulation that individual differences become relevant only under certain circumstances, for example, when the emotional response is particularly strong (Schmeichel \& Tang, 2015), or during other sub-processes of reappraisal. In this regard, results of two lesion studies by Salas and colleagues $(2013,2014)$ demonstrated that deficits in inhibitory control as measured by a stroop task were associated with deficits in the generation (vs. implementation) of possible reappraisal strategies. In other words, inhibitory control might rather represent an initial step in the generation of alternative appraisals, but might become less relevant once the alternative response is initiated. Clearly, this hypothesis needs to be addressed in further by investigating different samples, for example, subjects with 


\section{INHIBITORY CONTROL AND EMOTION REGULATION}

deficits in inhibitory control and/or emotion regulation, and by applying more fine-grained designs that allow to separate sub-processes of reappraisal.

Taken together, although inhibitory control seems like an obvious candidate contributor to emotion regulation, our findings corroborate the findings of previous studies and challenge the assumption that inhibitory control is related to individual differences in emotion regulation at the behavioral level. But is it reasonable to conclude that both control processes are not at all related? The answer is likely no, especially when it comes to the neural level. Besides the study by Tabibnia et al. (2011) that already demonstrated the right ventrolateral prefrontal cortex as a possible underlying substrate involved in both emotion regulation and inhibitory control processes, a more recent study by Beauchamp and colleagues (2016) addressed this issue further. In detail, the authors investigated behavioral and neural effects of an inhibitory control training (using a stopsignal task) on reappraisal ability in a comparable emotion regulation task. Although they found neither behavioral correlations nor an actual training effect, they observed activity in the left inferior frontal gyrus to be related to better performance in both paradigms.

Furthermore, an elegantly designed study by Depue and colleagues (2016) sheds new light on the complex relationship: by utilizing three tasks that require "inhibitory regulation" (among them a stop-signal and a reappraisal task comparable to ours), they identified three distinct inhibitory neural networks that each predicted performance in the individual tasks, as well as common activation across all tasks in the right medial frontal cortex. Comparable to our study, they found no relation between behavioral measures of inhibitory control and emotion regulation, arguing that the processes might diverge in their nature, with emotion regulation representing a more cognitive process compared to inhibitory control as a more behavioral process. Therefore, the general picture that emerges from our and other studies is that inhibitory control is not robustly associated with emotion regulation at the behavioral level and partly relies on a distinct neural network, but both processes also share a common neural substrate that likely plays an important role in inhibitory regulation across domains.

A last comment addresses the material over which inhibitory control is to be exerted. Critically, the study by Cohen and colleagues (2012) differed from ours as they used an emotional instead of non-emotional flanker task. Interestingly, they found a positive relationship between better performance in incongruent emotional flanker trials and the habitual use of reappraisal. Therefore, another alternative interpretation might be that reappraisal could rather be associated with inhibitory control over emotional instead of non-emotional material. In a similar vein, evidence 


\section{INHIBITORY CONTROL AND EMOTION REGULATION}

is accumulating that depressed participants show specific impairments only when the current task demands a trial-to-trial processing of emotional material compared to "pure" cognitive, nonemotional material (Saunders \& Jentzsch, 2014), and inhibition of negative content seems to be a shared process in rumination and reappraisal (N. Cohen et al., 2015). Clearly, further research with adequate tasks comparing "hot" and "cold" inhibitory control processes is needed to investigate this issue in more detail (see, for example, Saunders \& Jentzsch (2014) contrasting the classic and emotional-face stroop task).

Peripheral physiological measures and implementation of a full two-by-two design

Furthermore, we included a "regulate neutral" condition in a full two-by-two design and investigated whether the regulation effects generalize across valence categories (indicating a general regulation effect) or not (indicating a specific regulation effect for the respective emotion). Previous studies omitted this condition and argued that if a significant difference between a negative/positive and neutral viewing condition is present, the regulation effect is subsequently only investigated in the negative/positive condition (e.g., Moser et al., 2014; Schönfelder et al., 2014). However, this is comparable to a missing control group in clinical trials that is necessary to nullify external factors other than the treatment. Thus, the interpretation of the resulting regulation effect (e.g., the difference between negative permit and negative detach) remains ambiguous. It might represent the "true" regulation effort of the emotion under investigation. But it might also include the general regulation effort of implementing the respective strategy itself, irrespective of the specific emotion (e.g., generating the mindset of a detached observer, implementing the strategy including processes that support other strategies such as selective attention, memory, and performance monitoring).

Using our study design, corrugator EMG emerged as the only valid indicator of emotion regulation success that is specific to the regulation of negative emotion (compared to the regulation effort per se). That is, the difference between permit and detach was more pronounced for negative than for neutral stimuli in corrugator EMG, but not in SCR and HP. Instead, the latter demonstrated a significant main effect of strategy: during both negative and neutral pictures, SCR was significantly higher, and HP significantly reduced for permit compared to detach. Therefore, our results suggest that for HP and SCR, the regulation effort per se leads to characteristic changes (increased HP, decreased SCR), independent of the emotion that has to be regulated. Importantly, our results demonstrate that by investigating only negative pictures and omitting the "regulate neutral" condition, regulation effects can be over- and underestimated. This has important implications for future studies and highlights the need to include appropriate control conditions to disentangle general 


\section{INHIBITORY CONTROL AND EMOTION REGULATION}

from specific (emotion) regulation effects. Additionally, the corrugator response demonstrated a considerable effect size with $44 \%$ variance explanation (compared to SCR and HP with about $5 \%$ variance explanation). Thus, corrugator EMG represents a particularly suitable parameter for detecting peripheral physiological changes of emotion regulation.

A possible explanation for the partly diverging effects between corrugator EMG and SCR and HP, respectively, might rely in their temporal dynamics: Whereas facial EMG taps changes in muscle activity within milliseconds, SCR and HP changes can only be detected over a time window of several seconds. Especially the SCR is sluggish and delayed (peaks on average $3 \mathrm{~s}$ after stimulus onset; Dawson et al., 2007). Thus, it is possible that the regulation of emotions in a time window of only a few seconds is too small to be reliably detected with these measures. This is in line with studies that do find significant changes in HP and SCR during the regulation of emotions while watching video clips (Gross \& Levenson, 1993; Reynaud et al., 2012).

As far as we know, the present study provides the largest sample to date $(N=189)$ on peripheral physiological changes during emotion regulation. In contrast, the majority of studies included $N=10-50$ participants (Dan-Glauser \& Gross, 2011; Driscoll et al., 2009; Feeser et al., 2014; Jackson et al., 2000; Kalisch et al., 2005; Kim \& Hamann, 2012; Kinner et al., 2017; Ray et al., 2010; Schönfelder et al., 2014; Sheppes et al., 2009), with only Plieger et al. (2017) including $N$ $=97$ participants. The high statistical power allowed us to demonstrate that the correlations between peripheral physiological measures and self-reported valence and arousal ratings are likely below $r=$ .2. On the one hand, this is surprising. With SCR representing an objective measure of arousal and corrugator EMG representing an objective measure of valence (e.g., Bradley et al., 2001), we expected positive correlations between them. On the other hand, it is already known for decades that different autonomous and non-autonomous measures do not or only weakly correlate with each other (individual response stereotypy; Engel, 1960), and that self-reports can be biased (Paulhus \& Reid, 1991). Thus, our results emphasize the need to consider multiple measures simultaneously to obtain a comprehensive understanding of emotional responding and regulation.

\section{Limitations and future directions}

Despite the strong and consistent findings of our study, the generalizability of our results is limited to detachment as reappraisal strategy. The relationship of inhibitory control to other emotion regulation strategies, for example reinterpretation or expressive suppression, remains an open question for further investigations. Furthermore, we deliberately investigated young healthy adults without 


\section{INHIBITORY CONTROL AND EMOTION REGULATION}

cognitive control impairments and emotional dysfunctions, given that we were interested in the basic underlying mechanisms from an individual differences perspective. However, although this sample is appropriate to investigate underlying mechanisms in the relation of cognitive and emotional control, the variance in inhibitory control and emotion regulation ability might be limited by this design. This might have contributed to the lack of associations found here. Given the fruitful research on response inhibition as a valuable endophenotype for studying deficits in affective and impulse control disorders (e.g., depression, attention deficit hyperactivity disorder, schizophrenia; Joormann, 2010; Nigg, 2001; Westerhausen et al., 2011), future studies might focus on individuals with deficits in these conditions. In this regard, other studies such as Carlson and Wang (2007) and Lantrip and colleagues (2016) investigated preschool children and adolescents as opposed to our study in young adults. Several methodological differences might account for the inconsistent results on inhibitory control and emotion regulation, for example, the use of self-reports vs. performance measures, and the assessment of emotional expression vs. reappraisal.

\section{Conclusion}

In summary, we investigated the association between inhibitory control and emotion regulation in a large sample of young healthy adults. Despite the application of multiple laboratory tasks, utilizing a latent variable approach and considering several methodological issues related to the assessment of inhibitory control and emotion regulation, frequentist and Bayesian analyses indicated that both processes are not related at the behavioral level in a cross-sectional design. The results are in line with more recent studies that demonstrate a lack of behavioral effects and rather distinct neuronal networks associated with the regulation of cognitive and emotional processes (e.g., Beauchamp et al., 2016; Depue et al., 2016; Langner et al., 2018). Further work is needed to elucidate whether inhibitory control might still be related to emotion regulation, for example, by considering sub-processes of reappraisal generation vs. implementation, and by increasing the sampling precision (e.g., by selecting individuals with deficits in inhibitory control and/or emotion regulation). Furthermore, by implementing a full two-by-two design, our results provide evidence that domain-general regulation effects need to be separated from domain-specific regulation effects in order to avoid over- and underestimation of regulatory effects. Finally, as opposed to skin conductance response and heart period, corrugator EMG emerged as a suitable peripheral physiological predictor of reappraisal success. With its considerable amount of explained variance, corrugator EMG represents a particularly useful physiological indicator for the downregulation of negative affect. 


\section{INHIBITORY CONTROL AND EMOTION REGULATION}

\section{References}

Abler, B., \& Kessler, H. (2009). Emotion Regulation Questionnaire - Eine deutschsprachige Fassung des ERQ von Gross und John. Diagnostica, 55(3), 144-152. https://doi.org/10.1026/00121924.55.3.144

Aldao, A., Nolen-Hoeksema, S., \& Schweizer, S. (2010). Emotion-regulation strategies across psychopathology: A meta-analytic review. Clinical Psychology Review, 30(2), 217-237. https://doi.org/10.1016/j.cpr.2009.11.004

Bach, D. R. (2014). A head-to-head comparison of SCRalyze and Ledalab, two model-based methods for skin conductance analysis. Biological Psychology, 103, 63-68. https://doi.org/10.1016/j.biopsycho.2014.08.006

Bach, D. R., Daunizeau, J., Friston, K. J., \& Dolan, R. J. (2010). Dynamic causal modelling of anticipatory skin conductance responses. Biological Psychology, 85(1), 163-170. https://doi.org/10.1016/j.biopsycho.2010.06.007

Bach, D. R., Daunizeau, J., Kuelzow, N., Friston, K. J., \& Dolan, R. J. (2011). Dynamic causal modeling of spontaneous fluctuations in skin conductance. Psychophysiology, 48(2), 252-257. https://doi.org/10.1111/j.1469-8986.2010.01052.x

Bach, D. R., Flandin, G., Friston, K. J., \& Dolan, R. J. (2009). Time-series analysis for rapid eventrelated skin conductance responses. Journal of Neuroscience Methods, 184(2), 224-234. https://doi.org/10.1016/j.jneumeth.2009.08.005

Beauchamp, K. G., Kahn, L. E., \& Berkman, E. T. (2016). Does inhibitory control training transfer?: Behavioral and neural effects on an untrained emotion regulation task. Social Cognitive and Affective Neuroscience, 11(9), 1374-1382. https://doi.org/10.1093/scan/nsw061

Benjamini, Y., \& Hochberg, Y. (1995). Controlling the False Discovery Rate: A practical and powerful approach to multiple testing. Journal of the Royal Statistical Society. Series B (Methodological), $57(1), 289-300$.

Berntson, G. G., Quigley, K. S., Norman, G. J., \& Lozano, D. L. (2016). Cardiovascular psychophysiology. In J. T. Cacioppo, L. G. Tassinary, \& G. G. Berntson (Eds.), Handbook of psychophysiology (4th ed., pp. 183-216). Cambridge University Press. https://doi.org/10.1017/9781107415782.009

Bradley, M. M., Codispoti, M., Cuthbert, B. N., \& Lang, P. J. (2001). Emotion and motivation I: Defensive and appetitive reactions in picture processing. Emotion (Washington, D.C.), 1(3), $276-298$.

Bradley, M. M., \& Lang, P. J. (2000). Measuring emotion: Behavior, feeling, and physiology. In R. Lane \& L. Nadel (Eds.), Cognitive neuroscience of emotion (pp. 242-276). Oxford University Press.

Bratzke, D., Steinborn, M. B., Rolke, B., \& Ulrich, R. (2012). Effects of sleep loss and circadian rhythm on executive inhibitory control in the Stroop and Simon tasks. Chronobiology International, 29(1), 55-61. https://doi.org/10.3109/07420528.2011.635235

Buhle, J. T., Silvers, J. A., Wager, T. D., Lopez, R., Onyemekwu, C., Kober, H., Weber, J., \& Ochsner, K. N. (2014). Cognitive reappraisal of emotion: A meta-analysis of human neuroimaging studies. Cerebral Cortex, 24(11), 2981-2990. https://doi.org/10.1093/cercor/bht154 
Cai, R. Y., Richdale, A. L., Uljarević, M., Dissanayake, C., \& Samson, A. C. (2018). Emotion regulation in autism spectrum disorder: Where we are and where we need to go. Autism Research, 11(7), 962-978. https://doi.org/10.1002/aur.1968

Carlson, S. M., \& Wang, T. S. (2007). Inhibitory control and emotion regulation in preschool children. Cognitive Development, 22(4), 489-510. https://doi.org/10.1016/j.cogdev.2007.08.002

Cieslik, E. C., Mueller, V. I., Eickhoff, C. R., Langner, R., \& Eickhoff, S. B. (2015). Three key regions for supervisory attentional control: Evidence from neuroimaging meta-analyses. Neuroscience E3 Biobehavioral Reviews, 48, 22-34. https://doi.org/10.1016/j.neubiorev.2014.11.003

Cohen, J. (1988). Statistical power analysis for the behavioral sciences (2nd ed.). Lawrence Earlbaum Associates.

Cohen, N., Henik, A., \& Moyal, N. (2012). Executive control attenuates emotional effects - For high reappraisers only? Emotion, 12(5), 970-979. https://doi.org/10.1037/a0026890

Cohen, N., Mor, N., \& Henik, A. (2015). Linking executive control and emotional response: A training procedure to reduce rumination. Clinical Psychological Science, 3(1), 15-25. https://doi.org/10.1177/2167702614530114

Dan-Glauser, E. S., \& Gross, J. J. (2011). The temporal dynamics of two response-focused forms of emotion regulation: Experiential, expressive, and autonomic consequences. Psychophysiology, 48(9), 1309-1322. https://doi.org/10.1111/j.1469-8986.2011.01191.x

Dawson, M. E., Schell, A. M., Filion, D. L., \& Berntson, G. G. (2007). The electrodermal system. In J. T. Cacioppo, L. G. Tassinary, \& G. G. Berntson (Eds.), Handbook of psychophysiology (3rd ed., pp. 157-181). Cambridge University Press. https://doi.org/10.1017/CBO9780511546396.007

De Beni, R., Palladino, P., Pazzaglia, F., \& Cornoldi, C. (1998). Increases in intrusion errors and working memory deficit of poor comprehenders. The Quarterly Journal of Experimental Psychology Section A, 51(2), 305-320. https://doi.org/10.1080/713755761

De Lissnyder, E., Koster, E. H. W., Derakshan, N., \& De Raedt, R. (2010). The association between depressive symptoms and executive control impairments in response to emotional and nonemotional information. Cognition \&3 Emotion, 24(2), 264-280. https://doi.org/10.1080/02699930903378354

Demaree, H. A., Schmeichel, B. J., Robinson, J. L., Pu, J., Everhart, D. E., \& Berntson, G. G. (2006). Up- and down-regulating facial disgust: Affective, vagal, sympathetic, and respiratory $\begin{array}{llll}\text { consequences. } & \text { Biological } & \text { Psychology, } & \text { 71(1), }\end{array}$ https://doi.org/10.1016/j.biopsycho.2005.02.006

Dempster, F. N., \& Corkill, A. J. (1999). Individual differences in susceptibility to interference and general cognitive ability. Acta Psychologica, 101(2-3), 395-416. https://doi.org/10.1016/S00016918(99)00013-X

Depue, B. E., Orr, J. M., Smolker, H. R., Naaz, F., \& Banich, M. T. (2016). The organization of right prefrontal networks reveals common mechanisms of inhibitory regulation across cognitive, emotional, and motor processes. Cerebral Cortex, 26(4), 1634-1646. https://doi.org/10.1093/cercor/bhu324

Diers, K., Weber, F., Brocke, B., Strobel, A., \& Schönfeld, S. (2014). Instructions matter: A comparison of baseline conditions for cognitive emotion regulation paradigms. Frontiers in Psychology, 5. 


\section{INHIBITORY CONTROL AND EMOTION REGULATION}

https://doi.org/10.3389/fpsyg.2014.00347

Dörfel, D., Lamke, J.-P., Hummel, F., Wagner, U., Erk, S., \& Walter, H. (2014). Common and differential neural networks of emotion regulation by detachment, reinterpretation, distraction, and expressive suppression: A comparative fMRI investigation. NeuroImage, 101, 298-309. https://doi.org/10.1016/j.neuroimage.2014.06.051

Driscoll, D., Tranel, D., \& Anderson, S. W. (2009). The effects of voluntary regulation of positive and negative emotion on psychophysiological responsiveness. International Journal of Psychophysiology, 72(1), 61-66. https://doi.org/10.1016/j.ijpsycho.2008.03.012

Dunn, B. D., Billotti, D., Murphy, V., \& Dalgleish, T. (2009). The consequences of effortful emotion regulation when processing distressing material: A comparison of suppression and acceptance. Behaviour Research and Therapy, 47(9), 761-773. https://doi.org/10.1016/j.brat.2009.05.007

Engel, B. T. (1960). Stimulus-response and individual-response specificity. Archives of General Psychiatry, 2(3), 305. https://doi.org/10.1001/archpsyc.1960.03590090061010

Faul, F., Erdfelder, E., Buchner, A., \& Lang, A.-G. (2009). Statistical power analyses using G*Power 3.1: Tests for correlation and regression analyses. Behavior Research Methods, 41(4), 11491160. https://doi.org/10.3758/BRM.41.4.1149

Feeser, M., Prehn, K., Kazzer, P., Mungee, A., \& Bajbouj, M. (2014). Transcranial direct current stimulation enhances cognitive control during emotion regulation. Brain Stimulation, 7(1), 105112. https://doi.org/10.1016/j.brs.2013.08.006

Fridlund, A. J., \& Cacioppo, J. T. (1986). Guidelines for human electromyographic research. Psychophysiology, 23(5), 567-589. https://doi.org/10.1111/j.1469-8986.1986.tb00676.x

Friedman, N. P., Haberstick, B. C., Willcutt, E. G., Miyake, A., Young, S. E., Corley, R. P., \& Hewitt, J. K. (2007). Greater attention problems during childhood predict poorer executive functioning in late adolescence. Psychological Science, 18(10), 893-900. https://doi.org/10.1111/j.14679280.2007.01997.x

Friedman, N. P., \& Miyake, A. (2004). The relations among inhibition and interference control functions: A latent-variable analysis. Journal of Experimental Psychology: General, 133(1), 101-135. https://doi.org/10.1037/0096-3445.133.1.101

Funder, D. C., \& Ozer, D. J. (2019). Evaluating Effect Size in Psychological Research: Sense and Nonsense. Advances in Methods and Practices in Psychological Science, 2(2), 156-168. https://doi.org/10.1177/2515245919847202

Gärtner, A., Dörfel, D., Diers, K., Witt, S. H., Strobel, A., \& Brocke, B. (2018). Impact of FAAH genetic variation on fronto-amygdala function during emotional processing. European Archives of Psychiatry and Clinical Neuroscience. https://doi.org/10.1007/s00406-018-0944-9

Gärtner, A., \& Strobel, A. (2019). Individual differences in inhibitory control: A latent variable analysis. PsyArXiv. https://doi.org/10.31234/osf.io/gnhmt

Geurts, H. M., van den Bergh, S. F. W. M., \& Ruzzano, L. (2014). Prepotent response inhibition and interference control in autism spectrum disorders: Two meta-analyses. Autism Research, 7(4), 407-420. https://doi.org/10.1002/aur.1369

Gignac, G. E., \& Szodorai, E. T. (2016). Effect size guidelines for individual differences researchers. 


\section{INHIBITORY CONTROL AND EMOTION REGULATION}

Personality and Individual Differences, 102, 74-78. https://doi.org/10.1016/j.paid.2016.06.069

Giles, G. E., Cantelon, J. A., Eddy, M. D., Brunyé, T. T., Urry, H. L., Mahoney, C. R., \& Kanarek, R. B. (2017). Habitual exercise is associated with cognitive control and cognitive reappraisal success. Experimental Brain Research, 235(12), 3785-3797. https://doi.org/10.1007/s00221017-5098-x

Gross, J. J. (1998). The emerging field of emotion regulation: An integrative review. Review of General Psychology, 2(3), 271-299. https://doi.org/10.1037/1089-2680.2.3.271

Gross, J. J. (2015). The extended process model of emotion regulation: Elaborations, applications, and future directions. Psychological Inquiry, 26(1), 130-137. https://doi.org/10.1080/1047840X.2015.989751

Gross, J. J., \& Levenson, R. W. (1993). Emotional suppression: Physiology, self-report, and expressive behavior. Journal of Personality and Social Psychology, 64(6), 970-986.

Gyurak, A., Goodkind, M. S., Kramer, J. H., Miller, B. L., \& Levenson, R. W. (2012). Executive functions and the down-regulation and up-regulation of emotion. Cognition 83 Emotion, 26(1), 103-118. https://doi.org/10.1080/02699931.2011.557291

Gyurak, A., Goodkind, M. S., Madan, A., Kramer, J. H., Miller, B. L., \& Levenson, R. W. (2009). Do tests of executive functioning predict ability to downregulate emotions spontaneously and when instructed to suppress? Cognitive, Affective, \& Behavioral Neuroscience, 9(2), 144-152. https://doi.org/10.3758/CABN.9.2.144

Harnishfeger, K. K. (1995). The development of cognitive inhibition. In Interference and inhibition in cognition (pp. 175-204). Elsevier. https://doi.org/10.1016/B978-012208930-5/50007-6

Hofmann, W., Friese, M., \& Roefs, A. (2009). Three ways to resist temptation: The independent contributions of executive attention, inhibitory control, and affect regulation to the impulse control of eating behavior. Journal of Experimental Social Psychology, 45(2), 431-435. https://doi.org/10.1016/j.jesp.2008.09.013

Hot, P., Leconte, P., \& Sequeira, H. (2005). Diurnal autonomic variations and emotional reactivity. Biological Psychology, 69(3), 261-270. https://doi.org/10.1016/j.biopsycho.2004.08.005

Hot, P., Naveteur, J., Leconte, P., \& Sequeira, H. (1999). Diurnal variations of tonic electrodermal activity. International Journal of Psychophysiology, 33(3), 223-230. https://doi.org/10.1016/S0167-8760(99)00060-4

Hudson, A., \& Jacques, S. (2014). Put on a happy face! Inhibitory control and socioemotional knowledge predict emotion regulation in 5- to 7-year-olds. Journal of Experimental Child Psychology, 123, 36-52. https://doi.org/10.1016/j.jecp.2014.01.012

Jackson, D. C., Malmstadt, J. R., Larson, C. L., \& Davidson, R. J. (2000). Suppression and enhancement of emotional responses to unpleasant pictures. Psychophysiology, 37(4), 515-522. https://doi.org/10.1111/1469-8986.3740515

Joormann, J. (2010). Cognitive inhibition and emotion regulation in depression. Current Directions in Psychological Science, 19(3), 161-166. https://doi.org/10.1177/0963721410370293

Kalisch, R., Wiech, K., Critchley, H. D., Seymour, B., O'Doherty, J. P., Oakley, D. A., Allen, P., \& Dolan, R. J. (2005). Anxiety reduction through detachment: Subjective, physiological, and 
neural effects. Journal of Cognitive Neuroscience, 17(6), 874-883. https://doi.org/10.1162/0898929054021184

Kanske, P., Heissler, J., Schönfelder, S., Bongers, A., \& Wessa, M. (2011). How to regulate emotion? Neural networks for reappraisal and distraction. Cerebral Cortex, 21(6), 1379-1388. https://doi.org/10.1093/cercor/bhq216

Kim, S. H., \& Hamann, S. (2012). The effect of cognitive reappraisal on physiological reactivity and emotional memory. International Journal of Psychophysiology, 83(3), 348-356. https://doi.org/10.1016/j.ijpsycho.2011.12.001

Kinner, V. L., Kuchinke, L., Dierolf, A. M., Merz, C. J., Otto, T., \& Wolf, O. T. (2017). What our eyes tell us about feelings: Tracking pupillary responses during emotion regulation processes. Psychophysiology, 54(4), 508-518. https://doi.org/10.1111/psyp.12816

Kober, H. (2014). Emotion regulation in substance use disorders. In J. J. Gross (Ed.), Handbook of emotion regulation (2nd ed., pp. 428-46). Guilford Press.

Kohn, N., Eickhoff, S. B., Scheller, M., Laird, A. R., Fox, P. T., \& Habel, U. (2014). Neural network of cognitive emotion regulation-An ALE meta-analysis and MACM analysis. NeuroImage, 87, 345-355. https://doi.org/10.1016/j.neuroimage.2013.11.001

Lang, P. J., Bradley, M. M., \& Cuthbert, B. N. (1998). Emotion, motivation, and anxiety: Brain mechanisms and psychophysiology. Biological Psychiatry, 44(12), 1248-1263. https://doi.org/10.1016/S0006-3223(98)00275-3

Lang, P. J., Bradley, M. M., \& Cuthbert, B. N. (1999). International Affective Picture System (IAPS): Instruction manual and affective ratings: Vol. Center for Research in Psychophysiology. University of Florida.

Langner, R., Leiberg, S., Hoffstaedter, F., \& Eickhoff, S. B. (2018). Towards a human self-regulation system: Common and distinct neural signatures of emotional and behavioural control. Neuroscience \& Biobehavioral Reviews, 90, 400-410. https://doi.org/10.1016/j.neubiorev.2018.04.022

Lantrip, C., Isquith, P. K., Koven, N. S., Welsh, K., \& Roth, R. M. (2016). Executive function and emotion regulation strategy use in adolescents. Applied Neuropsychology: Child, 5(1), 50-55. https://doi.org/10.1080/21622965.2014.960567

Lee, H., Shackman, A. J., Jackson, D. C., \& Davidson, R. J. (2009). Test-retest reliability of voluntary emotion regulation. Psychophysiology, 46(4), 874-879. https://doi.org/10.1111/j.14698986.2009.00830.x

MacLeod, C. M. (2007). The concept of inhibition in cognition. In D. S. Gorfein \& C. M. MacLeod (Eds.), Inhibition in cognition. (pp. 3-23). American Psychological Association. https://doi.org/10.1037/11587-001

McRae, K., Jacobs, S. E., Ray, R. D., John, O. P., \& Gross, J. J. (2012). Individual differences in reappraisal ability: Links to reappraisal frequency, well-being, and cognitive control. Journal of Research in Personality, 46(1), 2-7. https://doi.org/10.1016/j.jrp.2011.10.003

Miyake, A., \& Friedman, N. P. (2012). The nature and organization of individual differences in executive functions: Four general conclusions. Current Directions in Psychological Science, 21(1), 8-14. https://doi.org/10.1177/0963721411429458 
Miyake, A., Friedman, N. P., Emerson, M. J., Witzki, A. H., Howerter, A., \& Wager, T. D. (2000). The unity and diversity of executive functions and their contributions to complex "frontal lobe" tasks: A latent variable analysis. Cognitive Psychology, 41(1), 49-100. https://doi.org/10.1006/cogp.1999.0734

Moser, J. S., Hartwig, R., Moran, T. P., Jendrusina, A. A., \& Kross, E. (2014). Neural markers of positive reappraisal and their associations with trait reappraisal and worry. Journal of Abnormal Psychology, 123(1), 91-105. https://doi.org/10.1037/a0035817

Nigg, J. T. (2000). On inhibition/disinhibition in developmental psychopathology: Views from cognitive and personality psychology and a working inhibition taxonomy. Psychological Bulletin, 126(2), 220-246. https://doi.org/10.1037/0033-2909.126.2.220

Nigg, J. T. (2001). Is ADHD a disinhibitory disorder? Psychological Bulletin, 127(5), 571-598.

Nigg, J. T., Wong, M. M., Martel, M. M., Jester, J. M., Puttler, L. I., Glass, J. M., Adams, K. M., Fitzgerald, H. E., \& Zucker, R. A. (2006). Poor response inhibition as a predictor of problem drinking and illicit drug use in adolescents at risk for alcoholism and other substance use disorders. Journal of the American Academy of Child 83 Adolescent Psychiatry, 45(4), 468-475. https://doi.org/10.1097/01.chi.0000199028.76452.a9

Ochsner, K. N., \& Gross, J. J. (2008). Cognitive emotion regulation: Insights from social cognitive and affective neuroscience. Current Directions in Psychological Science, 17(2), 153-158. https://doi.org/10.1111/j.1467-8721.2008.00566.x

Ochsner, K. N., Silvers, J. A., \& Buhle, J. T. (2012). Functional imaging studies of emotion regulation: A synthetic review and evolving model of the cognitive control of emotion. Annals of the New York Academy of Sciences, 1251(1), E1-E24. https://doi.org/10.1111/j.1749-6632.2012.06751.x

Pasolunghi, M. C., Cornoldi, C., \& De Liberto, S. (1999). Working memory and intrusions of irrelevant information in a group of specific poor problem solvers. Memory $\mathcal{E}$ Cognition, 27(5), 779-790. https://doi.org/10.3758/BF03198531

Paulhus, D. L., \& Reid, D. B. (1991). Enhancement and denial in socially desirable responding. Journal of Personality and Social Psychology, 60(2), 307-317. https://doi.org/10.1037/00223514.60.2.307

Paulus, P. C., Castegnetti, G., \& Bach, D. R. (2016). Modeling event-related heart period responses: Modeling event-related heart period responses. Psychophysiology, 53(6), 837-846. https://doi.org/10.1111/psyp.12622

Plieger, T., Melchers, M., Vetterlein, A., Görtz, J., Kuhn, S., Ruppel, M., \& Reuter, M. (2017). The serotonin transporter polymorphism (5-HTTLPR) and coping strategies influence successful emotion regulation in an acute stress situation: Physiological evidence. International Journal of Psychophysiology, 114, 31-37. https://doi.org/10.1016/j.ijpsycho.2017.02.006

Ray, R. D., McRae, K., Ochsner, K. N., \& Gross, J. J. (2010). Cognitive reappraisal of negative affect: Converging evidence from EMG and self-report. Emotion, 10(4), 587-592. https://doi.org/10.1037/a0019015

Reynaud, E., El-Khoury-Malhame, M., Blin, O., \& Khalfa, S. (2012). Voluntary emotion suppression modifies psychophysiological responses to films. Journal of Psychophysiology, 26(3), 116-123. https://doi.org/10.1027/0269-8803/a000074 


\section{INHIBITORY CONTROL AND EMOTION REGULATION}

Rothbart, M. K., \& Rueda, M. R. (2005). The development of effortful control. In U. Mayr, E. Awh, \& S. W. Keele (Eds.), Developing individuality in the human brain: A tribute to Michael I. Posner. (pp. 167-188). American Psychological Association. https://doi.org/10.1037/11108-009

Russell, J. A., Weiss, A., \& Mendelsohn, G. A. (1989). Affect Grid: A single-item scale of pleasure and arousal. Journal of Personality and Social Psychology, 57(3), 493-502. https://doi.org/10.1037/0022-3514.57.3.493

Salas, C. E., Gross, J. J., Rafal, R. D., Viñas-Guasch, N., \& Turnbull, O. H. (2013). Concrete behaviour and reappraisal deficits after a left frontal stroke: A case study. Neuropsychological Rehabilitation, 23(4), 467-500. https://doi.org/10.1080/09602011.2013.784709

Salas, C. E., Gross, J. J., \& Turnbull, O. H. (2014). Reappraisal generation after acquired brain damage: The role of laterality and cognitive control. Frontiers in Psychology, 5. https://doi.org/10.3389/fpsyg.2014.00242

Saunders, B., \& Jentzsch, I. (2014). Reactive and proactive control adjustments under increased depressive symptoms: Insights from the classic and emotional-face stroop task. Quarterly $\begin{array}{llll}\text { Journal of Experimental } & \text { Psychology, } & 67(5), & 884-898 .\end{array}$ https://doi.org/10.1080/17470218.2013.836235

Schmeichel, B. J., \& Tang, D. (2015). Individual differences in executive functioning and their relationship to emotional processes and responses. Current Directions in Psychological Science, 24(2), 93-98. https://doi.org/10.1177/0963721414555178

Schmidt, C., Collette, F., Cajochen, C., \& Peigneux, P. (2007). A time to think: Circadian rhythms in human cognition. Cognitive Neuropsychology, 24(7), 755-789. https://doi.org/10.1080/02643290701754158

Schönbrodt, F. D., \& Perugini, M. (2013). At what sample size do correlations stabilize? Journal of Research in Personality, 47(5), 609-612. https://doi.org/10.1016/j.jrp.2013.05.009

Schönfelder, S., Kanske, P., Heissler, J., \& Wessa, M. (2014). Time course of emotion-related responding during distraction and reappraisal. Social Cognitive and Affective Neuroscience, 9(9), 13101319. https://doi.org/10.1093/scan/nst116

Sheppes, G., Catran, E., \& Meiran, N. (2009). Reappraisal (but not distraction) is going to make you sweat: Physiological evidence for self-control effort. International Journal of Psychophysiology, 71(2), 91-96. https://doi.org/10.1016/j.ijpsycho.2008.06.006

Sheppes, G., Suri, G., \& Gross, J. J. (2015). Emotion regulation and psychopathology. Annual Review of Clinical Psychology, 11(1), 379-405. https://doi.org/10.1146/annurev-clinpsy-032814-112739

Simmons, J. P., Nelson, L. D., \& Simonsohn, U. (2012). A 21 Word Solution. SSRN Electronic Journal. https://doi.org/10.2139/ssrn.2160588

Simonds, J., Kieras, J. E., Rueda, M. R., \& Rothbart, M. K. (2007). Effortful control, executive attention, and emotional regulation in 7-10-year-old children. Cognitive Development, 22(4), 474-488. https://doi.org/10.1016/j.cogdev.2007.08.009

Stawski, R. S., Almeida, D. M., Lachman, M. E., Tun, P. A., \& Rosnick, C. B. (2010). Fluid cognitive ability is associated with greater exposure and smaller reactions to daily stressors. Psychology and Aging, 25(2), 330-342. https://doi.org/10.1037/a0018246 


\section{INHIBITORY CONTROL AND EMOTION REGULATION}

Strauss, G. P., Kappenman, E. S., Culbreth, A. J., Catalano, L. T., Lee, B. G., \& Gold, J. M. (2013). Emotion regulation abnormalities in schizophrenia: Cognitive change strategies fail to decrease the neural response to unpleasant stimuli. Schizophrenia Bulletin, 39(4), 872-883. https://doi.org/10.1093/schbul/sbs186

Tabibnia, G., Monterosso, J. R., Baicy, K., Aron, A. R., Poldrack, R. A., Chakrapani, S., Lee, B., \& London, E. D. (2011). Different forms of self-control share a neurocognitive substrate. Journal of Neuroscience, 31(13), 4805-4810. https://doi.org/10.1523/JNEUROSCI.2859-10.2011

Uhmann, S., Wendsche, J., Tomaschek, A., \& Richter, P. (2008). Multimethod validation of a screening instrument for job related affective well-being. International Journal of Psychology, 43(3-4), 61. https://doi.org/10.1080/00207594.2008.10108483

Urry, H. L. (2009). Using reappraisal to regulate unpleasant emotional episodes: Goals and timing matter. Emotion, 9(6), 782-797. https://doi.org/10.1037/a0017109

Urry, H. L. (2010). Seeing, thinking, and feeling: Emotion-regulating effects of gaze-directed cognitive reappraisal. Emotion, 10(1), 125-135. https://doi.org/10.1037/a0017434

Webb, T. L., Miles, E., \& Sheeran, P. (2012). Dealing with feeling: A meta-analysis of the effectiveness of strategies derived from the process model of emotion regulation. Psychological Bulletin, 138(4), 775-808. https://doi.org/10.1037/a0027600

Wessa, M., Kanske, P., Neumeister, P., Bode, K., Heissler, J., \& Schönfelder, S. (2010). EmoPicS: Subjektive und psychophysiologische Evaluation neuen Bildmaterials für die klinischbiopsychologische Forschung [EmoPicS: Subjective and psychophysiological evaluation of new imagery for clinical biopsychological research]. Zeitschrift Für Klinische Psychologie Und Psychotherapie, Supplement, 1/11(77). Michèle Wessa, wessa@uni-mainz.de

Westerhausen, R., Kompus, K., \& Hugdahl, K. (2011). Impaired cognitive inhibition in schizophrenia: A meta-analysis of the Stroop interference effect. Schizophrenia Research, 133(1-3), 172-181. https://doi.org/10.1016/j.schres.2011.08.025

Wolff, M., Krönke, K.-M., Venz, J., Kräplin, A., Bühringer, G., Smolka, M. N., \& Goschke, T. (2016). Action versus state orientation moderates the impact of executive functioning on real-life selfcontrol. Journal of Experimental Psychology: General, 145(12), 1635-1653. https://doi.org/10.1037/xge0000229 